encourage the further collection and full interpretation of works now committed to memory which may otherwise be lost to future students of African history and culture.

\title{
The Papers of Sir Joseph Banks
}

THE Library of the Royal Geographical Society has recently acquired xerographic prints of two sets of papers which are of considerable importance for the history of African exploration. This has come about as the result of a search for papers bearing on the history of the 'Association for the Discovery of the Interior Parts of Africa', which, founded in 1788 , was amalgamated with the Royal Geographical Society in 1830 . On that occasion, the R.G.S. apparently received none of the Association's documents. It seemed probable that a likely resting-place for them would be with the papers of Sir Joseph Banks, a founder of the Association and later President of the Royal Society from 1778 to 1820 . His papers are now distributed among numerous libraries throughout the world. On the suggestion of Miss Mander Jones, formerly Librarian of the Mitchell Library, Sydney, an approach was made to Mr. Richard H. Dillon, Libratian of the Sutro Library, California State Library, San Francisco. Mr. Dillon very kindly allowed the section of Banks's papers in his Library dealing with African affairs to be microfilmed, and from these films enlarged prints have been made by the Rank-xerox process. These prints amount to approximately 900 sheets, including a few printed pamphlets, and include letters to and from Sir Joseph Banks on actual or potential African travellers from 1788 to I 820 , documents concerning the organization, meetings, and finances of the Association, papers on the trading ventures of the African Company and the Sierra Leone Company, and memoranda and notes on a variety of subjects, such as the introduction of plants into Sierra Leone, possibilities of establishing communications and trade with the interior, and the appointment of consuls. It is hoped that these papers will shortly be thoroughly calendared.

A further line of inquiry led to the location of the three manuscript minute books of the Association in the University Library, Cambridge. These had formed part of the collection bequeathed to the Museum of Classical Atchaeology by Colonel William Martin Leake, the last Honorary Secretary of the African Association. Through the good offices of Mr. H. R. Cheswick, University Librarian, the Library Syndics generously presented to the Royal Geographical Society a microfilm of these three folio volumes, which cover the complete lifetime of the African Association, and constitute the primary source for any assessment of its role in the history of the modern exploration of Africa. They are also of special interest to the Royal Geographical Society, since it was the latter which took over and widened, during the nineteenth century, the work of African exploration inaugurated by the Association in the closing decades of the eighteenth century. But for the outbreak of the Napoleonic wars, it is not going too far to suggest, the foundation of the R.G.S. might have been antedated by twenty years. The Society therefore plans to publish an annotated edition of these minute-books as a first step towards the inauguration of its own record series.

[Communicated by Mr. G. R. Crone]

\section{The Journal of African History}

The Journal of African History, the first number of which has recently appeared, is edited by R. A. Oliver and J. D. Fage, with an advisory editorial board composed of representatives from African, Belgian, British, French, and United States universities. The first issue of the Journal contains ten articles and a large number of book reviews.

Contributions may be in English or French and should be addressed to: The Editors, Journal of African History, School of Oriental and African Studies, University of London, 